\title{
M-Library in an m-University: Changing Models in the Open University of Catalonia
}

\author{
Dora Pérez \{aperez@uoc.edu\} \\ Pep Torn \{jtorn@uoc.edu\}
}

\section{Introduction}

One of the early images used by the Universitat Oberta de Catalunya (Open University of Catalonia, UOC) to explain its educational model when it was created in 1995 was that of a young man seated under a tree working on his laptop computer. The image was not so specific as to be able to determine whether the student was working in his garden, in a city park or in the middle of a mountain range, but it was evident that he was a student "on the move".

The spirit of the UOC includes mobility. The appearance of mobile technologies: $\mathrm{m}$ technologies, of new and ever more mobile devices than the first laptop computers of the 1990s: $m$-devices, and of suitable formats for consultation using these devices: $m$-formats, is a panorama of continuity for the universities like ours that made a commitment to ICT from the start as the basis of their project and to virtuality as a medium.

Virtuality today, however, is a widely implemented model on the world university, and evidently, the Spanish, scene, and has consequently ceased to be the exclusive domain of the original distance universities. There are many degrees, courses or subjects that are offered in elearning or blended learning formats by the traditional universities, and this means, among other things, that the collections and services of the libraries of all these universities have adapted this model to a greater or lesser extent.

What's the case then of mobile devices, the latest to appear on the virtuality scene? What is the implication for the UOC and its library regarding the adaptation of collections and services for this type of device?

In this document, we have looked at the Spanish situation with regard to $m$-technologies on the basis of surveys conducted between April and May 2009 with the directors of Spanish university libraries. At the same time, we show the path taken and the present situation of the UOC, the university where we work, in terms of the use of $m$-technologies, $m$-formats and $m$-devices. 


\section{M-libraries in Spain.}

In Spain, there are at present 73 universities. The libraries of 70 universities, of which $70 \%$ are publicly-owned and 30\% privately-owned, almost all of the Spanish university libraries, and the libraries of the state research centre, Consejo Superior de Investigaciones Ciéntificas (CSIC) make up the REBIUN network (Spanish University and Scientific Libraries Network). Rebiun is a university library network that shares, with greater or lesser involvement by each one, the development of a common strategic plan, collaborative work on projects of shared interest, etc.

A study was made of these libraries to find out the level of development of access to contents and services using mobile devices.

The study consisted of sending a survey to all the Spanish university libraries with the aim of finding out the level of implementation of $m$-technologies in Spain.

The survey was sent using the distribution list used by the directors of the libraries and consisted of just three questions with the aim of its being easy to answer and to obtain a good percentage of response in order to get a broad view of the use of these services and of the present interest of libraries in this new line.

The questions were:

a. Does your library have or is it planning to have any type of service that can be accessed using any mobile device?

b. What type of service accessible from mobile devices does your library offer?

c. What devices are used to access these services?

Out of the 71 libraries, a total of 63 have replied to the survey, i.e. almost 90\%, meaning that we feel that the sample is highly significant of the Spanish situation. 


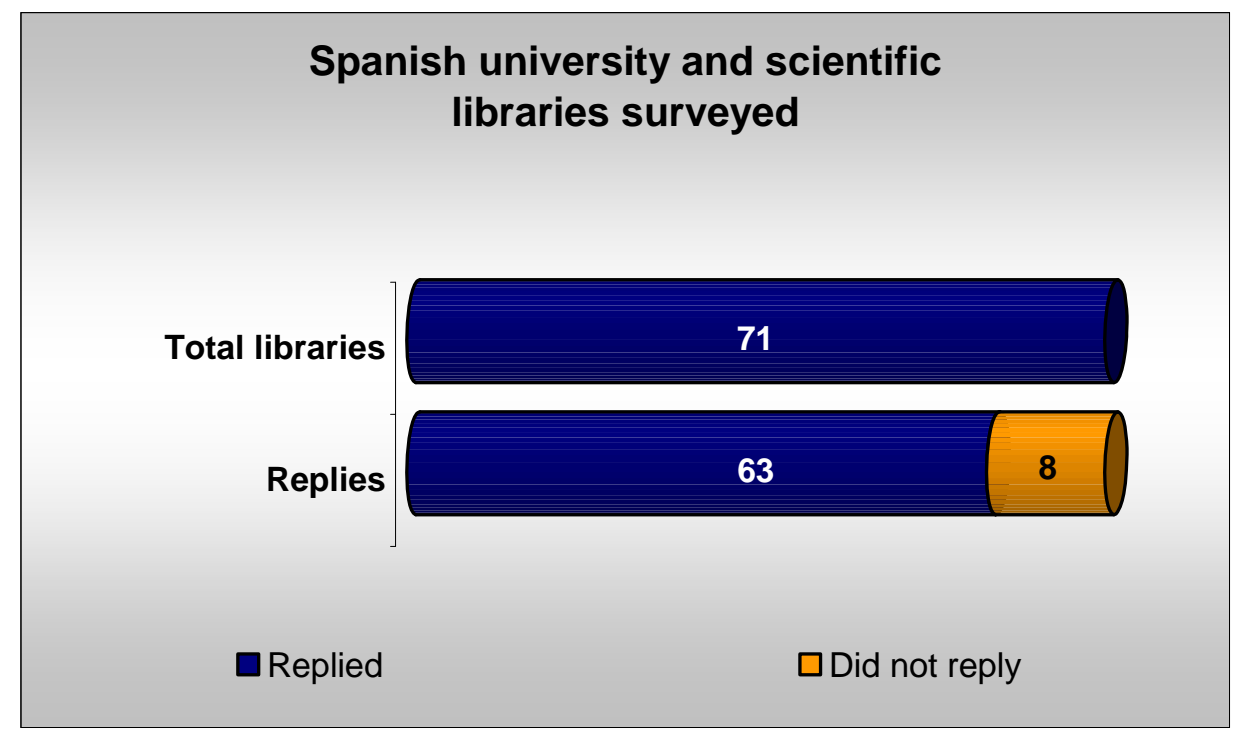

- Fig. 1. REBIUN libraries surveyed -

Of the 63 libraries that replied, 18 have access to services via mobile devices, 45 do not have these services and 18 are planning them. It should be noted that of the 18 libraries that are planning services, at the time of the survey 12 had no service of this type in operation and 6 have some service in operation but are planning new services of this type to offer to their users.

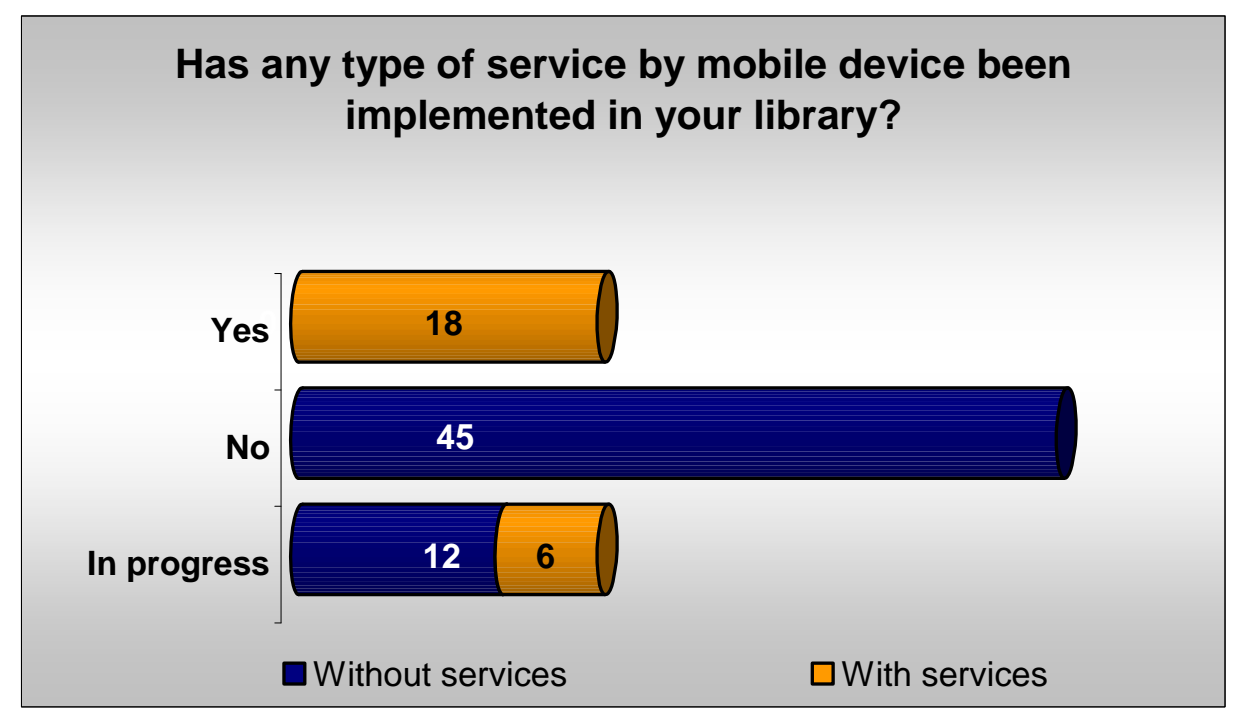

- Fig. 2. Libraries with or without $m$-technologies implemented -

\section{1. m-libraries services.}

In light of the survey, 4 categories of service have been identified: document lending service, general information service, OPAC-related service, e-text oriented service. 


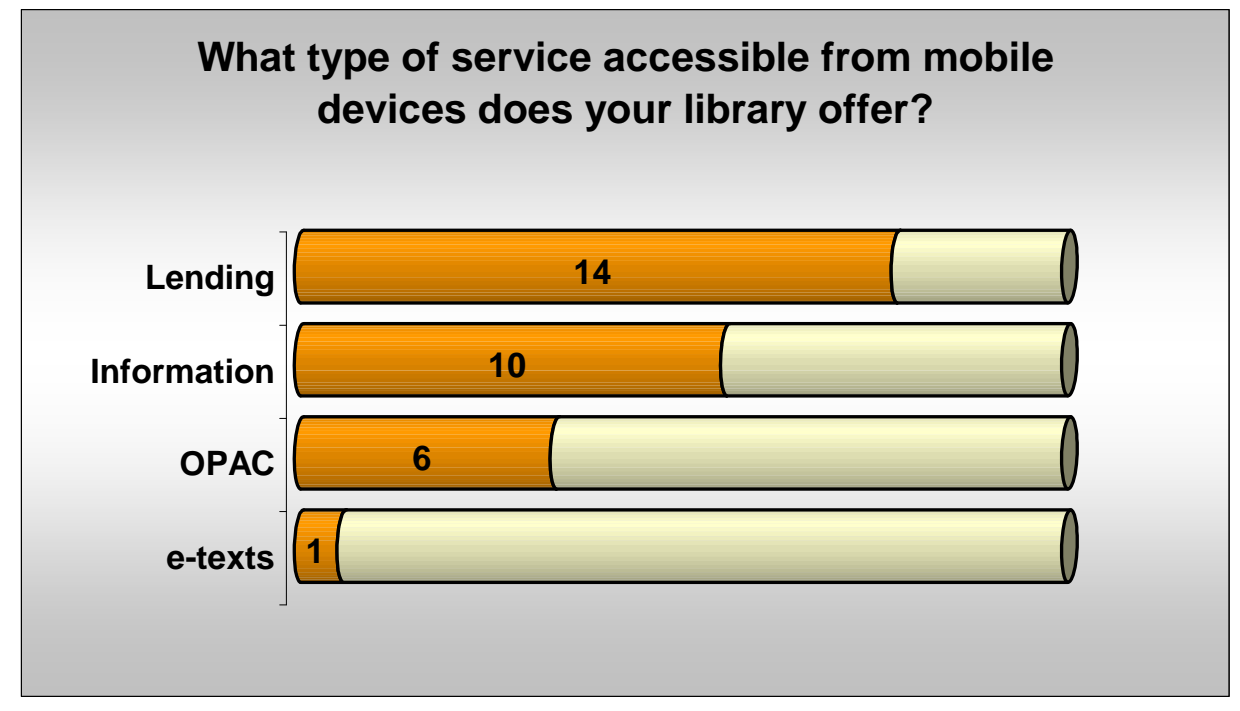

- Fig. 3. Types of service implemented -

Of the 18 libraries that have implemented services, 14 of them have services related to the lending of physical documents: renewals, overdue claims, reservations, etc. A total of 13 more libraries are planning this type of service. We should note that almost all the libraries surveyed are on-site libraries, with the exception of the UOC (Universitat Oberta de Catalunya) and the UNED (National Distance Education University), and that, therefore, the lending service is very important for all of them. The most numerous actions related to document lending are overdue claims (8 libraries), followed by reservations (7 libraries) and renewals (5 libraries). Very few libraries (3) allow their users to request documents on loan via mobile devices.

In numerical terms, the lending service is followed in importance by the information service (10 libraries provide it and 5 are implementing it), which includes different types of reply: library opening times, information about the lending service, new items, etc. We should note here a service offered by the UOC, which provides its users with thematic news services, of varying frequency, by means of various devices.

Access to OPACs via mobiles and PDA also has a leading position in services using mobile devices. A total of 6 libraries offer this service and 5 libraries are working towards offering it.

Finally, just one library ${ }^{1}$ offers access to e-texts, although 3 more libraries are about to start up this service.

\footnotetext{
${ }^{1}$ It should be remembered that we are evaluating libraries. There are several universities that offer collections of e-texts and access to e-book devices from other university units or departments apart from the library.
} 


\subsection{Devices and technologies in the $m$-libraries}

The devices used to access the services described above are divided into the following technologies: mobile telephone in general, Short Message Service (SMS) and PDA.

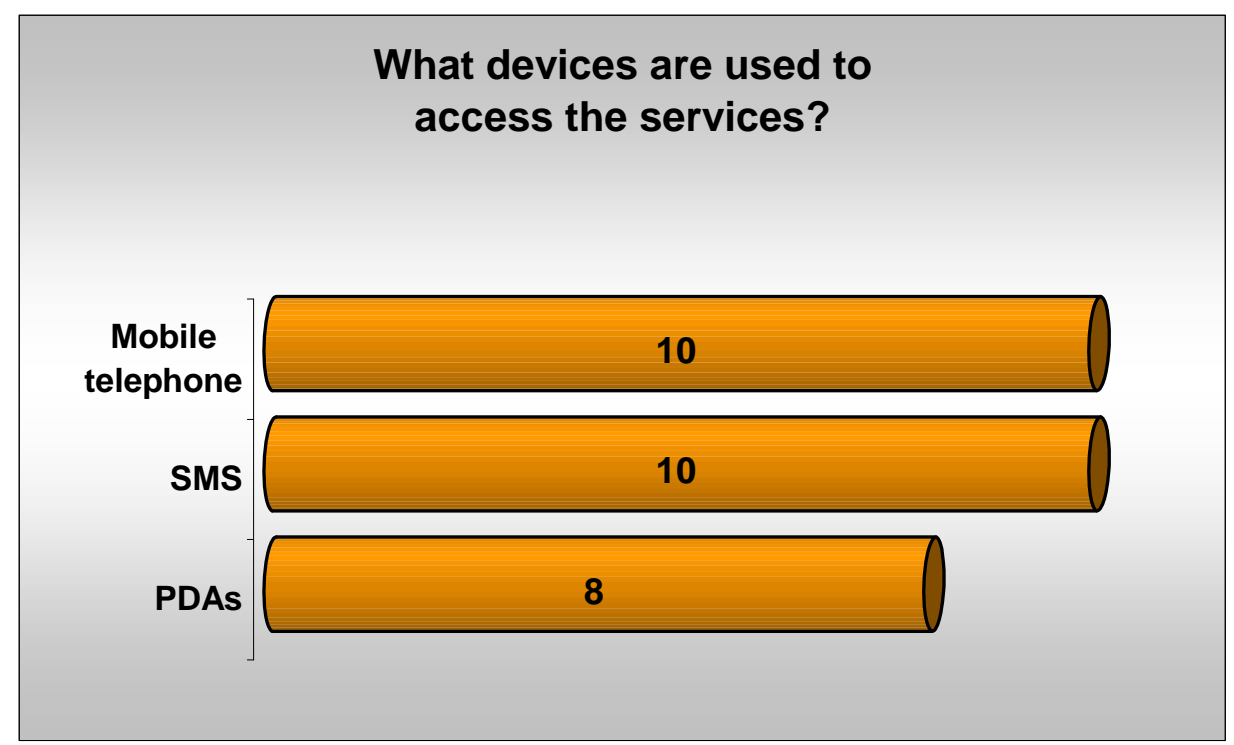

- Fig. 4. Devices used -

The SMS service is the most widely used one for renewals, reservations and overdue claims of the document lending services, while the mobile telephone, followed by PDAs, are the most widely used for accessing the OPAC and information services.

\subsection{Planned services}

A total of 18 libraries are planning services via mobile devices. The majority of these libraries (12) do not presently have services but are working towards implementing some. The remaining 6 are libraries that already have services in operation but are planning to extend this range.

Almost all the libraries have offered us information about the projects that they are planning, and the vast majority are tending towards services related to document lending (13), some are considering offering information services and access to the OPAC (5), and 3 of them are preparing e-books collections and devices.

There are also 3 that are planning to adapt the whole website so that it is accessible using different devices. 


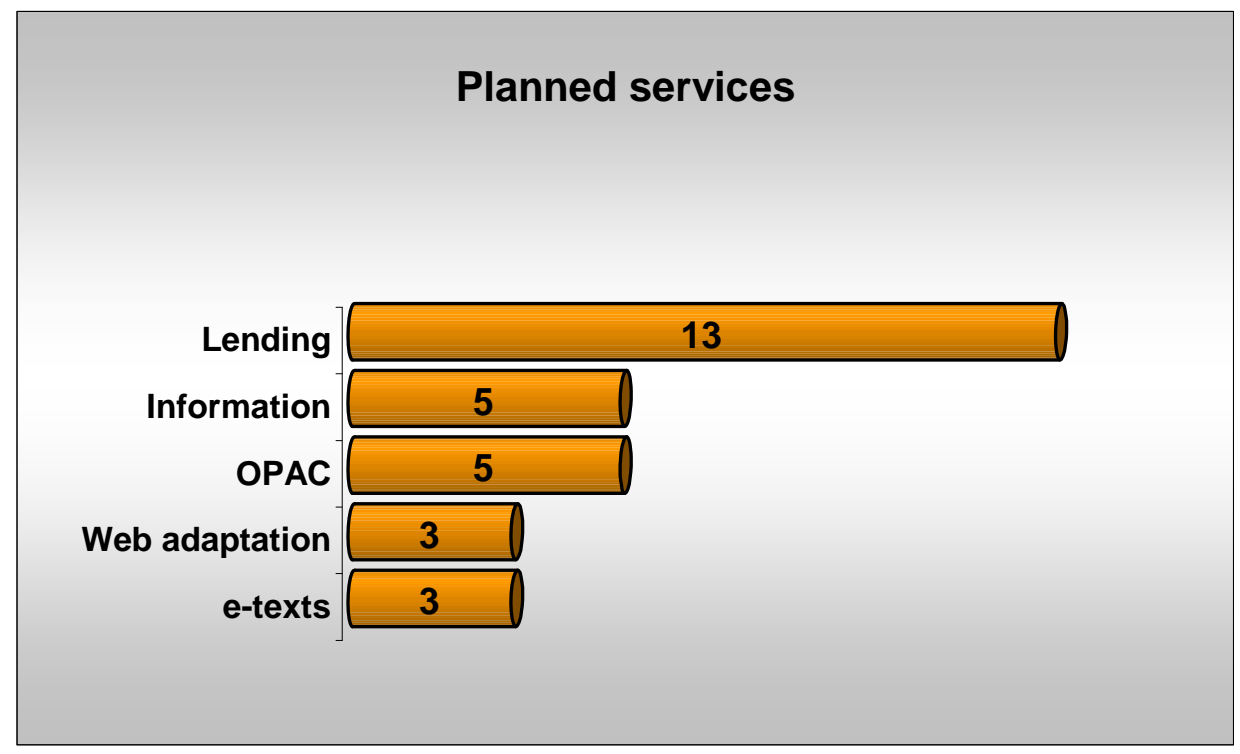

- Fig. 5. Planned m-services -

The devices or technologies for access to planned services are based primarily on SMS and the mobile telephone in the great majority of projects. A trend is starting in the use of e-books to provide access to e-texts and make them available to the users by means of the lending system.

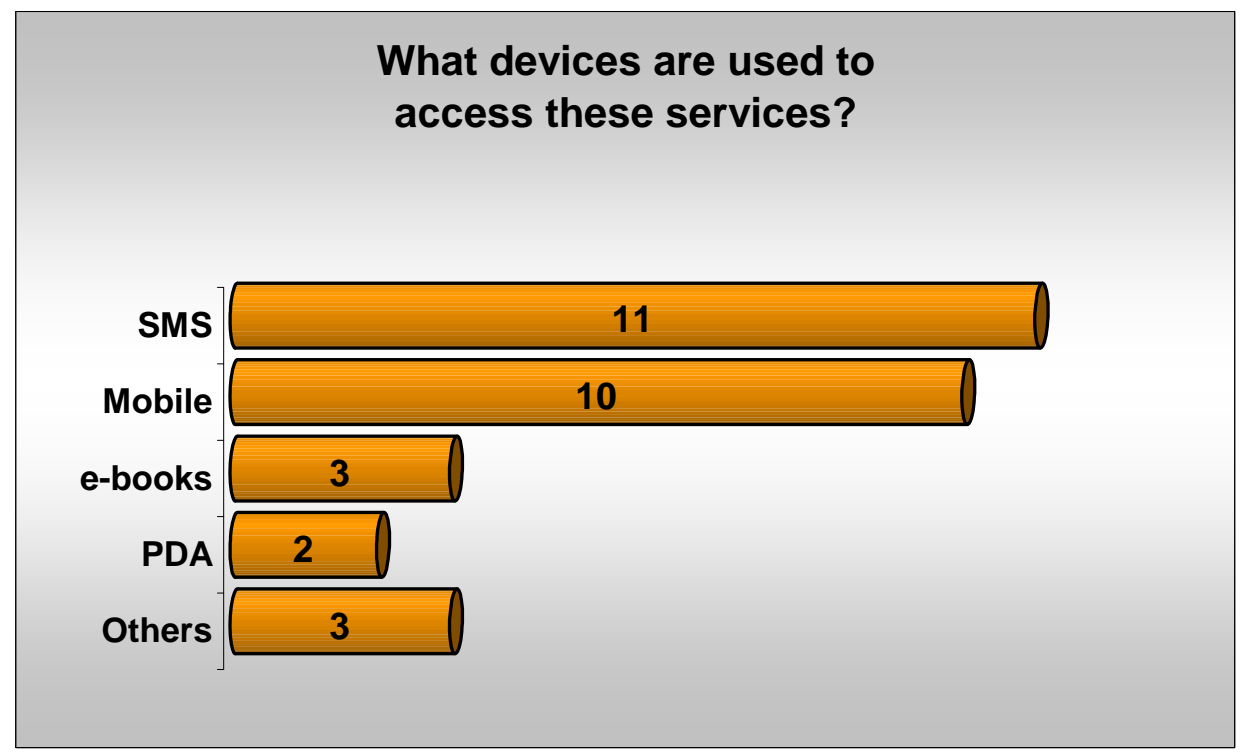

- Fig. 5. Planned m-devices -

\subsection{Conclusions of the Spanish situation}

The conclusions that can be extracted from the study conducted show that although it is not the main concern of libraries, many of them are interested in providing their users with access to the library without having to go there in person. 
At a European-level professional get-together in June 2009 (attended by Spanish library directors), participants were asked to identify the trends of the coming 2-3 years in their libraries, where 10 were identified. When asked to reduce this further to leave it at 3 trends that they saw as key, one of the 3 finalists was the application of mobile technologies.

Going back to the survey conducted, $29 \%$ of the libraries surveyed have already started down this road, and a further $19 \%$ will probably be added to this figure by late 2009 or early 2010 , with which we will have $48 \%$ of Spanish university libraries soon offering services accessible from mobile devices despite their being on-site libraries.

If advances are made in the downloading of e-texts of use to students and lecturers, this service may be adopted by a fair few libraries, as there are presently numerous libraries that are offering or are about to offer an e-book lending service, although without adequate contents.

Experience tells us that at a Spanish level, common undertakings offer better results than individual developments. Work in environments such as consortia or professional networks have enabled us to achieve a level of adaptation to ICT, of professionalisation of human resources and of accesses to collections far greater than the initial ones. It is interesting to discover that the commitment to the creation of m-libraries is an aim shared by many Spanish universities, while when proposing projects, defining objectives or sharing experiences, it will prove to be easier to gear actions towards successful outcomes.

\section{The Universitat Oberta de Catalunya, the library and m-technologies}

Apart from the transfer of research to society carried out by the UOC Internet Interdisciplinary Institute (IN3), there is a significant part of the innovation carried out at the university that is studied and developed for application within the university. The educational, communicative, service, etc. model of a virtual university undergoes constant updating, and the UOC is a test bench of all the technological innovations that can be applied in the university environment to improve all aspects.

It is in this environment that the UOC made a commitment in the 2000 s to research into the incorporation of mobile technology to offer services to the virtual community. The first developments were through SMS (Short Message Systems) and WAP. 


\subsection{The OPAC and WAP technology}

In February 2000, the UOC became the first Spanish university to offer Virtual Campus contents using Wireless Application Protocol (WAP) technology. In light of the potential of this new technology and its growth forecasts, it was felt that it opened up a new opportunity for libraries to offer their services and resources using these new devices.

The structure of the WAP server was implemented on Windows NT using Nokia Wap Server. The services that were implemented with this technology throughout the university were:

- $\quad$ Procedures with the Secretariat

- Academic calendar

- Information about Support Centres

- Mailbox

- New features on the Virtual Campus

- $\quad$ Access to the Library OPAC

For access to the Library OPAC, which at that time used the VTLS software, on ORACLE, the Virtual Web Gateway was duplicated to enable a web listener by WAP. This PERL web gateway was recoded to adapt the output in HTML to VML language used by WAP devices, and the number of results was limited to 5 by 5 instead of 20 because of the size of the devices' screens.

Accessing from the main menu, the user found the search option with the usual different possibilities: author, title, subject area, subject. The editor that was incorporated in the device assisted the entry of the search argument, sent the information to the server and, after a few seconds, the search results were received.

It seemed at that time that the following WAP generations would allow new services to be offered, so the Library prepared the development of a system of reserving loan documents and access to the e-documents available in the UOC catalogue, with information about their location in the central warehouse or at the different support centres that the UOC has all over the region.

\subsection{GPS, SDI and Reservations}

Another line of work was that of informing the user of the location of the nearest document to the place where the reservation was made, using GPS, and the possibility of receiving the different "push" services that had been implemented in the Library at the time: SDI (Selective Information Dissemination), the different themed news services, etc.

Another development in this vein was that of using SMS technology: taking advantage of the development made by the university in sending marks using SMS, work was carried out on 
adapting this system for sending document lending transactions, specifically sending confirmations of loan reservations and overdue loans claims.

The results and conclusions that were reached in the development of these new technologies is that Internet access by mobile telephone would allow users access to information without depending on computers and terrestrial communications. This phenomenon implied a new opportunity for libraries to offer and adapt their services to this new environment. Within the context of the university, the UOC Library offered the services developed over some years to the virtual community as a complement or alternative to access via computer.

Owing to other priorities, the university did not pursue the development with mobile technologies, and therefore the Library also abandoned its developments, which were not feasible if the university did not make advances in incorporating these technologies into the Virtual Campus.

In the same vein and at the same time, the Libraries Coordination Unit of the Higher Science Research Council (CSIC) collaborated on the project World Wide Web Information Server of the Pacific Science Commission (II): Digital Dissemination Systems of Cultural Heritage (TIC 20000168-P4-04), which considered access to an information system using WAP mobile telephony.

\subsection{M-technologies in the UOC}

The present situation is rather complex. With the widespread adoption by the public of mobile telephones as a means of communication, the range of services on offer and the proposed projects by the UOC are very extensive.

In terms of its extensive use, the most notable by the university is the sending of final marks in the subjects to users' telephones individually. This system has been in use since the 2000-2001 academic year. However, the library does not participate in this project.

One of the other remarkable projects is the one carried out this academic year on a number of postgraduate courses or individual subjects, where all students enrolled have been provided with an e-book device (iRex iLiad), which contains all the teaching modules of the subjects that the student is studying. This project has been carried out as a pilot trial and the assessment by the students has been uneven.

The specific case of the Digital Literacy subject has been analysed in depth in order to find out the level of satisfaction and suitability to the users' needs.

The students analysed are all those on Humanities courses, divided between psychology, educational psychology and humanities courses. It is also a highly expert population in the university environment, with $90 \%$ of them studying on their second degree at the UOC and all 
having studied 2 terms or more at the university. It is a group with proven skills in the use of office technology (all UOC students have to prove this through a mandatory subject before enrolling on the degree course). The average age of the users to whom the device was provided is 33 , and they are primarily (>60\%) women.

Contrary to what one may have thought in view of the profile of the sample, the first surprise of the Educational Technology team when analysing the project was that, generally speaking, no one knew the operation, the general utility and, evidently, the technical operation of the devices. $100 \%$ of the users analysed resorted to the internet to know how to make the equipment work.

Especially remarkable is that $100 \%$ of the users have continued to use the rest of the usual materials and tools at the UOC to pass the subjects in question, such that we could say that they have seen the device as a non-essential reinforcement tool.

We believe that this should be understood in the specific context of the UOC, where the students who have worked using the virtual campus for a number of terms know the work methodology and have incorporated it into their way of understanding studying. Therefore, it is really an alternative rather than a main option to use a device like the iRex iLiad. More so when use could be made of the materials of the subjects without using the mobile device.

The aspects that the students saw as most positive were, on the one hand, the possibility of the device allowing not only the teaching materials to be read, but also to store extra information generated by them, and on the other the ease of reading onscreen, which they consider to be more useful than that of a laptop computer.

The evaluation made by the UOC department that has conducted this pilot trial is generally positive. The most remarkable aspects that Educational Technology staff highlighted on completion of the pilot trial are, to begin with, the modernity and improvement of the image of the institution. At a practical level, they stress the ease of sending materials, as they are not reliant on messaging services to send materials, which can be sent over the virtual campus and which the user can download on paper; this aids the simultaneity of distribution. Finally, we should also highlight the ecological aspect implied by the saving of paper in the use of electronic ink devices.

At the end of the course, the students were able to buy the device by paying $50 \%$ of the original price, and the result was that $25 \%$ of the students decided to buy them for their own personal use.

The library did not participate directly in this case either, although precisely $40 \%$ of the devices returned by the students have been provided to the library for their incorporation into its collection and for them to be offered on loan. 


\subsection{Current m-technologies and m-projects in the library}

The involvement of the library in this period, which we could call second era, is still rather initial. After analysis of the first era of developments and commitments under the WAP system, greater caution is taken before committing to specific technologies.

Next September, we will be starting the 2009-2010 academic year with a range of 18 e-books devices at the UOC libraries. Of these 18 , there are 15 that are from the returns of the students on the postgraduate Open-Source Software course; these devices are the iRex iLiad model, which allow consultation of the teaching materials of many UOC subjects. The 3 remaining devices are iRex $D R$ 1000, which have an A4-size screen and which allow all the teaching materials of all UOC subjects to be read.

The commitment of the library is to offer these materials on loan in a very similar way to how the rest of the books on paper are offered, as we understand that the format should not determine the offer and we treat devices on the basis of their content, i.e. as thought they were another book.

The content that we make available to users for consultation via e-books is included on a library webpage and ranges from the teaching materials created by the UOC for all its various subjects and programmes, to material from the Library's digital collection. The library's Documentary Resources team has conducted an exhaustive analysis of the documentary sources bought by the library to resolve which ones can be consulted using the iRex. This way, the user can have access to a significant collection to supply the device.

The other projects on which the library is working are at the expense of other technological solutions with which all the Library's resources are managed. The libraries in the Catalan University Library Association (CBUC) jointly acquired the Innovative Millennium, SFX and Metalib documentary management software, and it is in this environment where we have worked the hardest.

\subsection{Conclusions}

In light of the proliferation of mobile technologies among our users, the m-library concept is a value to which we are strongly committed, but in which we have to take firmer and more secure steps than those we took previously. The first experience in the commitment to WAP technology tells us that we need to combine with the other technology departments at the UOC with a view to making a commitment to one or more technologies with which to work on the subjects relating to the m-library that we want to develop. 
At a markedly technological university, the aspects relating to implementations of new technologies are of great importance. The UOC is supported by a complex structure where the technology support teams used by all the departments is key, such that part of the technological knowledge is not in the library but in the teams that provide support to the library from other areas. There are primarily two departments responsible for ICT support for the library: Applications \& Processes and Educational Technology, and the steps that we take from now on in the commitment to mobile technologies have to be agreed upon with both departments.

The strongest commitment made by the library in recent months - the acquisition of the $18 \mathrm{e}$ books readers - has been on the basis of the joint work with the Educational Technology department. This way, we ensure the support of the institution in the event of any problems with the devices, training needs or needs to share knowledge.

With regard to the $m$-technologies trends with which the library considers it is suitable to work, we should say that we have our reservations in terms of devices, which are presently barely used among the public. Although it is true to say that the UOC seeks to be a trendsetter in Catalonia and Spain in aspects of innovation, it is also true to say that users set the agenda in part when it comes to defining the communicative tools to which we should be making a commitment.

We need to have a good knowledge of the environment in which we will be working on future trends, and the Catalan and Spanish case is highly particular. An EU study conducted in 2006 placed Spain above the European average in mobile telephone penetration, specifically with $94 \%$ of users with a mobile telephone, whereas the EU as a whole stands at $92.8 \%$.

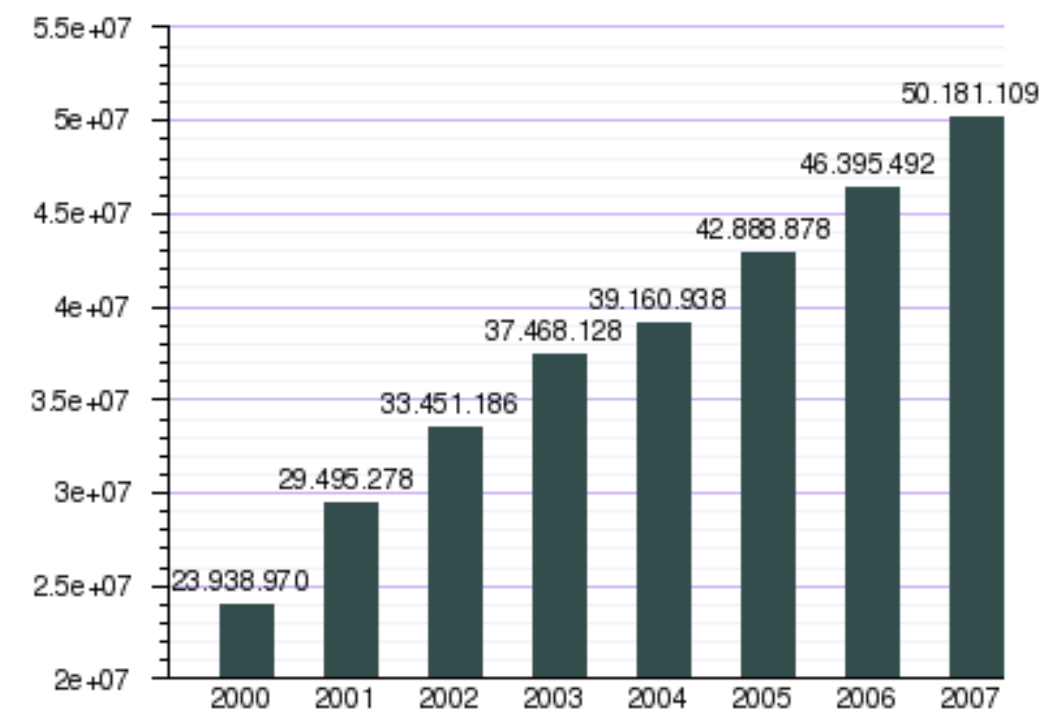

- Fig. 6. Evolution of the number of mobile telephone lines in Spain between 2000 and 2007 (Source: Red.es Observatory) - 
Although anticipating user needs is important, sticking our neck out to think that users will choose to buy mobile devices other than telephones massively is rather risky.

In a recent conversation between David W. Lewis (Dean of the IUPUI University Library and Indiana University) and a number of directors of Catalan university libraries, Lewis offered the following question for reflection: what is the age of the users that we have seen holding an electronic ink device? Generally speaking, we could say that they are all rather older. By contrast, the age of the people we know that use a mobile telephone every day offers an immense diversity.

In this environment, we at the UOC Library see mobile telephones as a technology of the future to which the Library should devote a large part of its efforts, and electronic ink devices a field that we should approach more cautiously.

Although we regard our library, like every other library in the world, as an area with a certain degree of autonomy in some aspects, the library's wish is for shared work with all the areas in the university, and the whole university is involved in permanent technological change, in such a way that the UOC should develop a facet of adoption of m-technologies as a whole, and the library in particular. A virtual university such as the UOC should also be an m-university and have, among other things, an m-library.

Besides this, and in the same way that we feel that shared work between libraries from all over Spain can be enriching when defining the model(s) of m-libraries on which to work, the UOC Library, as a member of the CBUC, is immersed in an environment with various documentary management products. These products are primarily and presently software related to or compatible with Millennium, SFX and Metalib.

It is in these environments that we are directing our efforts in order to adapt the present virtual library to a virtual library for mobile devices. At present, we are considering the possibility of incorporating the Millennium AIRPAC module (which allows consultation of the OPAC for mobiles and PDA) and SMS Notice module (which allows alerts to be sent relating to the circulation of collections) into the library catalogue.

We trust that the Innovative and Ex Libris developments also follow this direction, because the UOC Library, urged on by the commitment of the users, has started out on a road towards mobility that will stop only if the users ask for it.

\section{References}

Ally,M., (et al.). "Use of a Mobile digital library for Mobile learning". M-Libraries : libraries on the move to provide virtual access / edited by Gill Needham and Mohamed Ally. London : Facet, 2008. pp. 217-227

Arroyo-Vázquez, N. "Web móvil y bibliotecas". El profesional de la información, 2009, marzoabril, v. 18, n. 2, pp. 129-136.

DOI: 10.3145/epi.2009.mar.02 
Horizon Report 2009. Johnson, Laurence F., Levine, A., and Smith, Rachel S. 2009 Horizon Report. Austin, TX: The New Media Consortium, 2009.

http://www.nmc.org/news/nmc/horizon-2009-translations

Keegan, D. (2005). The incorporation of mobile learning into mainstream education and training. Paper presented at the World Conference on Mobile Learning, Cape Town.

Keegan, D. (2003). The future of learning: From elearning to mlearning. Retrieved September 13, 2006, from http://learning.ericsson.net/mlearning2/project_one/book

López-de-la-Fuente, José-Manrique. "Merkur: herramienta de transcodificación parametrizada de contenidos". El profesional de la información, 2009, marzo-abril, v. 18, n. 2, pp. 218-222. DOI: 10.3145/epi.2009.mar.12

Quin, C. (2000). mLearning: Mobile, Wireless, In-Your-Pocket Learning. LiNE Zine, Fall 2002. Available at: http://www.linezine.com/2.1/features/cqmmwiyp.htm

Serrano, Jordi. "Acceso a la Biblioteca de la UOC por medio de la telefonía Móvil". I Jornadas de Bibliotecas Digitales. Valladolid, 6-7 noviembre 2000 http://biblioteca.uoc.edu/

Sheikh, H., Eales, S., Rico, M. "Open Library in tour pocket - services to meet the needs of onand off-campus users". M-Libraries : libraries on the move to provide virtual access / edited by Gill Needham and Mohamed Ally. London : Facet, 2008, pp. 187-196

Tin,T., Sheikh, H., Elliott, C., "Designing and developing e-learning content for mobile platforms: a collaboration between Athabasca University and Open University". M-Libraries : libraries on the move to provide virtual access / edited by Gill Needham and Mohamed Ally. London : Facet, 2008, pp. 173-183

Zawacki-Richter, O. Brown, T., \& Delport, R. (2009). "Mobile Learning: From single project status into the mainstream?". European Journal of Open, Distance and E-Learning. EURODOL.

Zawacki-Richter, O., Brown, T., \& Delport, R. (2007). Factors that may contribute to the establishment of mobile learning in institutions - Results from a survey. International Journal: Interactive Mobile Technologies (iJIM), 1(1), 40-44.

http://www.eurodl.org/materials/contrib/2005/Zawacki Richter.htm

Zawacki-Richter, O. (2005). Online Faculty Support and Education Innovation - A Case Study. European Journal of Open and Distance Learning (EURODL), Volume 1. Available at http://www.eurodl.org/materials/contrib/2005/Zawacki Richter.htm 